\title{
COMPARATIVE REVIEW OF THE RISK ASSESSMENT QUANTITATIVE MODELS FOR PUBLIC OPEN SPACES LIGHTING DESIGN OPTIMISATION
}

\author{
Ivan Milorad Rakonjac* \\ Unicons University, Faculty of Project and Innovation Management, Belgrade, Serbia \\ Ivana Milorad Rakonjac \\ University of Belgrade, Faculty of Architecture, Belgrade, Serbia \\ Miloš Petar Gašić \\ University of Belgrade, Faculty of Architecture, Belgrade, Serbia
}

The key focus in the paper is on the presentation of the risk assessment model in the optimisation design process by establishing the link between the various phases that result in the successful project implementation. Through the comparative analysis of the quantitative risk assessment models a number of impacts on the design process are shown which occur in different project phases. This approach has proved the RAKA model (Risk Analysis by Key-factors Assessment) to be the most adequate mathematical model for the assessment of the risks on the project goals in the optimisation process of the development of the products for the accomplishing lighting of the open public spaces. The particularities of the model are best described by the predetermined criteria which contribute to the optimisation of the design process through the quantitative analysis of the project risks, according to the predetermined project goals sets. The influence of the risks on the project goals are shown by mathematical formulas in which the criteria of the design team are taken into account, leading to the efficiency improvement and enhancement in the implementation phases of the project. Key words: Risk management, New product development, User needs, Ambiance value

\section{INTRODUCTION}

Primary aim of the lighting in a public open space is to enable perception of the elements in space and provide a safe environment for the users in the night hours. The importance of the lighting lies in achieving the primary aim through yielding a pleasant ambiance and providing a desirable visual experience by accentuation of the architectural values in space. A favourable lighting should provide not only minimal ambiance lighting which reveals the points of risk and enables orientation, but also the emphasis on the architectural values (Rakonjac et al. 2016). The optimisation of the lighting design process of the public spaces is possible through appropriate activity in the development phase of the industrial products for public space lighting. The production process of the urban lighting equipment is determined by the requirements which derive from the lighting design process which is influenced by the user needs, as well as the conditions of the spe- cific space. Therefore, it is of vital significance to determine the requirements and to systematically follow the process of their fulfilment from the very beginning of the development process, by documentation and information flow (Ninkovic et al. 2012). Every deviation from the requirements can be tracked in the later phases of the design process in multiple ways. Risk management is a very important aspect within this concept.

\section{RISK MANAGEMENT}

Risk management in the design process of the projects has been recognised in previous research (Cooper, 2003; Kayis, Arndt, \& Zhou, 2007, Stamenkovic et al. 2011), but it was not sufficiently considered in literature, especially when a new industrial product development is aimed (Keizer, Vos, \& Halman, 2005; Gidel et al. 2005). Empirical research in this field is rarely applied (Oehmen et al. 2014). The importance of the quantitative risk analysis in the design process of the public space light 
ing was presented in the paper (Rakonjac et al. 2011) along with the mathematical model for the assessment of the level of influence of the risks to the project goals, by the acronym RAKA (Risk Analysis by Key-factors Assessment). Risk management is the process which is treated by the model in the industrial product development process aimed for the lighting of the public spaces. This process is the integral part of the project management and it is depicted as a system on the Figure 1. The concept of the system is based on the impact of the managerial structure within the system of the project, devoted to the achievement of certain project goals.

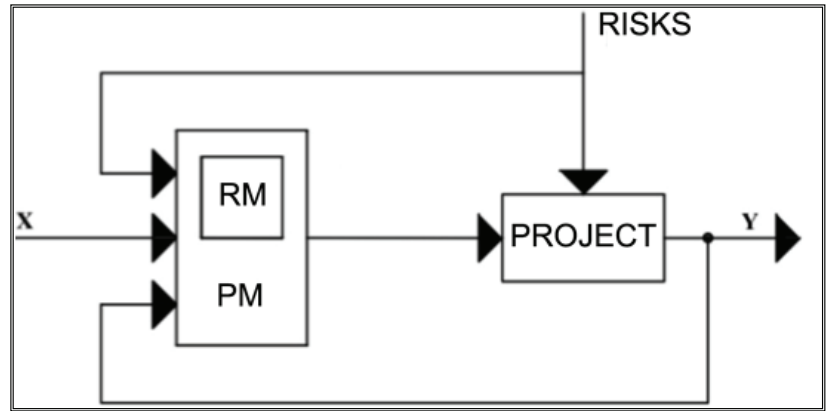

Figure 1: Block diagram of the project management process

PM stands for the project management structure, while RM stands for project risks management. The input variables to the system are presented by the predetermined project goals, while the output variables show the accomplished values. These variables can be shown as input vectors $X=\left(x_{1}, x_{2}, x_{3}, \ldots, x_{n}\right)$ and output vectors $Y=\left(y_{1}, y_{2}, y_{3}, \ldots, y_{n}\right)$ respectively, with the elements $\left(x_{1} x_{2}, x_{3}, \ldots, x_{n}\right)$ displaying the wanted outcomes followed by the realised goals $\left(y_{1}, y_{2}, y_{3}, \ldots, y_{n}\right)$. The risk represents a disturbance in the system, namely an unpredicted change of variables which influences the outputs of the system. These disturbances can be generated within system (internal risks) or outside of the system (external risks).

The disturbance occurrence in the system causes deviations of the realised project goals in comparison to desired (predetermined) project goals. This deviation is called an error. Hence, the very notion of disturbance, or risk, is directly attached to the notion of error. The equation 3.1 shows the error for the i pair of the input-output variables.

$$
Z_{i}=X_{i}-Y_{i}
$$

Having in mind the unstable nature of risk, one disturbance can lead to the error occurrence simultaneously at multiple pairs of input-output variables. Also, a set of disturbances can provoke an error for one pair of input-output variables.

Since a risk can have positive or negative effect on the project goals (PMI 2008, Ward 2010) equivalently the nature of disturbance will result with the error occurrence in the system which would be characterised as favourable if it has a positive influence on the project goals, or unfavourable if it has negative influence on the project goals. The nature of the error is stochastic in most of the cases (Gidel et al. 2005, Stanisavljev et al. 2015). Figure 2 depicts the characteristic of the error.

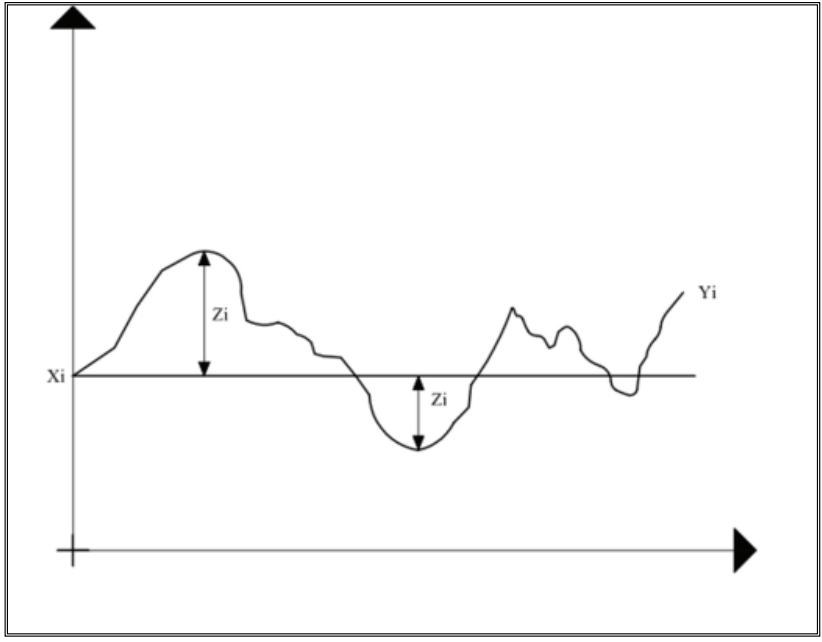

Figure 2: Characteristic of the error

The managerial structure of the system inclines towards direct, proactive and/or corrective compensation for the disturbance, by means of feedback. If the error is favourable, it has to be taken advantage of, so that the project goals would be met or even surpassed. If the error is unfavourable, compensation is needed. To make this process feasible, it is necessary to apply some of the appropriate models for quantitative assessment of the system disturbance level, i.e. risk. Based on the previous considerations, as well as the known nature and mechanisms for project risks quantification, the following systems features can be identified:

- Input system variables represent the desired project goals;

- Output system variables represent the achieved project goals;

- An error occurs by deviation of the achieved from the desired project goal; 
- System disturbances are project risks.

- One disturbance can provoke the occurrence of multiple errors in the system;

- Multiple disturbances can provoke the occurrence of one error in the system;

- Probability of the error occurrence in the system is directly linked to the probability of the risk occurrence;

- Probability of (non)detection of the error occurrence is directly linked to the (non)detection of the risk occurrence,

- Probability of the error appearance in the system is determined by the probability of the occurrence and the probability of (non)detection of the system error;

- The error magnitude signifies a relative measure of deviation of the output to the input variable, and it is directly influenced by the magnitude of the risk consequences;

- The favourable error occurs under the effects of risks which are identified as opportunities.

- The unfavourable error occurs under the effects of risks which are identified as threats.

- The total disturbance level of the system is called the risks sum and represented as the function of the error occurrence and the error magnitude.

Since the set of the systems features is defined, one can approach to identifying the available mathematical models for the risk assessment.

\section{MODELS FOR THE QUANTITATIVE PROJECT RISKS ANALYSIS}

After all the available approaches were analysed, their deficiencies were ascertained as well as their advantages, the principles for selecting the model can be established.

The framework of the model should have the quality to enable a wide array of application, and the relevant approach towards complexity. The model has to be complex to the extent in which the project of the public space is complex.

The probability of the risk occurrence is additionally determined by the feature of manifestation, namely how the system disturbance is revealed, by multiplying the occurrence probability with the (non)detection probability of the actual disturbance.
The assessment of the error magnitude, which represents the impact or the consequence of the risk event on the project goals in terms of the plan and the budget, should be displayed by a simple function. On the other hand, modelling of the technical product features is left to the user, given the particularities of the process of the industrial product development which is subject to the project risks quantification. In this case, the product is the equipment for the lighting of the open public spaces.

There is often confusion when it comes to terminology in the project risks management, and the mix up of the notions (Carbone and Tipett, 2004). It is therefore necessary to uniformly define the variables.

A comparative view of several available models for the risks quantification is provided in the Table 3.1. The models can be applied on the project of industrial product development for the lighting of the open public spaces.

After reviewing the Table 1 it can be noted that the models proposed by Carbone and Tippett (2004) and by Kerzner (2009) are different from the RAKA model since the risks recognised as the opportunities are not taken into account. In addition, the quantification result has different purpose.

Kerzner (2009) uses the mathematical function which determines the risk factor as the multiplication of the failure probability factor and the failure consequence, as follows:

$F=P_{f}+C_{f}-P_{f} C_{f}$

where $P_{f}$ stands for the probability of failure and $C_{f}$ for the consequence of failure.

The RFMEA (Carbone i Tippett 2004) introduces a tool that is relatively simple and intuitive. By modification of the standard FMEA format, in the RFMEA the concept of risk presentation is expanded by adding the attribute of risk detection. In this way, a new value is added to the model which allows for more precise calculation of the risk level and the priority number of risks. However, the major drawbacks of this model are incapability of generalisation of the variables, and the necessity to have internal scales and the risk legend.

In the standard FMEA process, modalities of failure are appraised by occurrence, severity and detection of collapse. 
Table 1: Comparative view of the project risks quantification models

\begin{tabular}{|c|c|c|c|c|}
\hline & $\begin{array}{c}\text { RAKA model } \\
\text { Rakonjac et al. (2011) }\end{array}$ & $\begin{array}{c}\text { RFMEA } \\
\text { Carbone and } \\
\text { Tippett (2004) }\end{array}$ & $\begin{array}{c}\text { Risk Value Method } \\
\text { Browning et al. (2002), } \\
\text { Browning and Hillson } \\
(2003)\end{array}$ & $\begin{array}{c}\text { Risk } \\
\text { assessment } \\
\text { model } \\
\text { Kerzner (2009) }\end{array}$ \\
\hline \multirow[t]{5}{*}{ Terminology } & $\begin{array}{c}\text { Probability of error } \\
\text { appearance }\end{array}$ & I & Probability, Uncertainty & $\begin{array}{l}\text { Probability of } \\
\text { failure }\end{array}$ \\
\hline & $\begin{array}{l}\text { Probability of error } \\
\text { occurrence }\end{array}$ & Likelihood & l & l \\
\hline & $\begin{array}{c}\text { Probability of (non) } \\
\text { detection }\end{array}$ & Detection & l & l \\
\hline & Error magnitude & Impact & Consequence, Impact & $\begin{array}{l}\text { Consequence } \\
\text { of failure }\end{array}$ \\
\hline & Risk (Disturbance) & Risk Event & Risk & Risk \\
\hline $\begin{array}{c}\text { Threats/ } \\
\text { opportunities }\end{array}$ & Combined effect & Threats & Combined effect & Threats \\
\hline $\begin{array}{l}\text { Quantification } \\
\text { Result }\end{array}$ & $\begin{array}{l}\text { Risks sum (the level } \\
\text { of risk on the project } \\
\text { goals) }\end{array}$ & $\begin{array}{l}\text { Risk score } \\
\text { Risk priority } \\
\text { number }\end{array}$ & $\begin{array}{l}\text { Risk value (the level of risk } \\
\text { on the project goals) }\end{array}$ & $\begin{array}{l}\text { Risk factor (total } \\
\text { effect to all the } \\
\text { project goals) }\end{array}$ \\
\hline $\begin{array}{c}\text { Result } \\
\text { representation }\end{array}$ & {$[0,1]$} & $\begin{array}{c}\text { Internal scale, } \\
\text { risk legend }\end{array}$ & {$[0,1]$} & {$[0,1]$} \\
\hline
\end{tabular}

By multiplying these three values, the risk priority number (RPN) is obtained:

$$
R P N=O S D
$$

where $\mathrm{O}$ stands for $\mathrm{t}$ he occurrence of failure, $\mathrm{S}$ for the severity of failure, and $D$ for the detection of failure.

Besides the risk priority number RFMEA model incorporates the risk score as multiplication of the likelihood and the impact (Carbone and Tippett 2004).

The risk value method proposed by Browning et al. (2002), which is described in more detail in the paper from Browning and Hillson (2003) represents the model that describes the product attributes by the utility functions. The model is described by the following equation:

$J=\left(\phi_{1}, \phi_{2}, \ldots, \phi_{m}\right)$

$U=\left(U\left(\phi_{1}\right), U\left(\phi_{2}\right), \ldots, U\left(\phi_{m}\right)\right)$

in which $\phi$ stands for the product attributes, $\mathrm{J}$ for the vector of the $m$ attribute of the product, and $U$ for the utility function, which assigns one number to each option of the given attribute $\mathrm{J}$.
Even though the risk detection cannot be taken in consideration by this model, it is essentially very similar to the RAKA model. If the terminology distinctions are set aside, as well as the fact that RAKA model includes the concept of detection probability, or probability of not detecting the error, depending on the error deriving from either opportunity or threat, there are differences in the functions which connect these variables. The "Risk Value Method" (Browning et al. 2002, Browning and Hillson, 2003) has focus on the quantitative analysis of highly complex systems, presenting the risk value as the integral of the multiplication of the probability and the impact for all the risk outcomes. On the other hand, through the RAKA model the impacts of all the risks (both opportunities and threats) which influence all the project goals are integrated. In this way, the approach to the quantification of risks sum is simplified, since it is often not possible to ascertain the influence of every single risk to the deviations of the achieved project goal in comparison to the predetermined goal, especially when the effects of all the risks are combined. 
The above considerations can be explained by the formula:

$R_{l}=\left\{\sum_{i=1}^{m_{q}} k_{l i} P_{e l i} \cdot P_{d i}^{x_{i}}-\sum_{i=m_{\eta+1}}^{m_{i}} k_{t j} P_{e l i} \cdot P_{d i}^{\prime}\right\} \cdot\left(1-C_{l}\right)+C_{l}$

where the abbreviations stand for:

$P_{e i}^{\prime}, P_{d i}^{\prime}, P_{e i}^{\prime \prime}, P_{d i}^{\prime \prime}, k_{i} \in S_{l}, n_{l}$ - total number of the elements of the project goal set $S_{l}$,

$m_{l}$ total number of the elements of the set $S_{l}$ identified as the threats,

$\left(\mathrm{n}_{\mathrm{i}}-\mathrm{m}_{\mathrm{i}}\right)$ - number of the elements of the set $S_{l}$ identified as the opportunities,

$C_{l}$ - consequence of the error, where $/$ stands for the predefined project goal,

$P_{e}^{\prime}$ - probability of the occurrence of the unfavourable error,

$\mathrm{P}_{\mathrm{d}}{ }^{\prime}-$ probability of not detecting the error due to the risk classified as the threat,

$P_{e}$ " - probability of the occurrence of the favourable error,

$P_{d}$ "'- probability of detecting the error due to the risk classified as the opportunity.

The RAKA model allows for the quantitative assessment of the risks sum for combined effects of the identified set of risks on the project goal.

The universal nature of the RAKA model can be seen from the fact that all the variables are determined on the interval, so that there is no need for an additional legend or a key to understand the quantitative risk levels. Also, this model equally encompasses the threats and the opportunities, making the quantification of the combined influence of all the risk events on project goals possible. This also implies the risk level estimation for all the determined project goals, which may prove as valuable information in the process of risk action planning. The application of the model in industrial product development for the lighting of the public open spaces particularly contributes to the advancements in the lighting design process. These advancements can foremost be identified as the savings of time in the design process, and also in the implementation phase of the projects of the lighting of the public open spaces.

\section{CONCLUSION}

It can be concluded that all of the reviewed models can be applied in practice. However, in cases when the focus is on the risk management in the optimisation process for the lighting design of the public open spaces, it is of critical importance to incorporate the combined risks influence on the project goals, taking the threats as well as the opportunities into account. Of all the presented models only the RAKA model makes this approach possible.

As previously explained, to achieve a successful lighting design project of the open public space it is important to address the requests that determine needs for undisturbed activities flow, as well as obtaining the aesthetic values. This can be accomplished through the design of the urban lighting equipment, including previously mentioned technical and aesthetic features. Considering that the ergonomic and aesthetic criteria are included in the RAKA model, its contribution is apparent in the advancement of the lighting design process by optimisation of the lighting equipment in the development and production phases. Since the end users and their needs are envisioned by the model, the requirements for more efficient functional lighting are better met and the security and safety issues more adequately addressed. These improvements can be noted in both the design and implementation phase of the project. On the other hand, by emphasizing the aesthetic criteria of the product in the risk management model it is possible to achieve a step forward in harmonising the urban lighting equipment appearance with the architectural value system. Determination of these ergonomic and aesthetic criteria would enable more successful light effects achievements in the process of design, which contributes to an adequate ambience and the space aura.

Considering that the open space lighting can be regarded as an obligatory element within any urban space structure, the RAKA model can also be implemented in the field of the trade export promotion (Spasojević-Brkić el al. 2015). The RAKA model proves as an universal risk assessment model for the urban city spaces design process, because it answers the need to achieve both functional lighting and to accentuate architectural and ambience space values in the process of industrial product development for the open public space lighting. 


\section{REFERENCES}

1) Browning, T. \& Hillson, D. (2003). „A quantitative framework for multi-dimensional risk and opportunity management", Working Paper, Texas Christian University, Neely School of Business, pp. 1-28.

2) Browning, T.R., Fricke, E. \& Negele, H. (2006) „Key concepts in modeling product development processes“, Systems Engineering 9(2), pp.104-128.

3) Carbone, T.A. \& Tippett, D.D. (2004) "Project Risk Management Using the Project Risk FMEA", Engineering Management Journal, 16(4), pp.28-35.

4) Cooper, L.P. (2003). "A research agenda to reduce risk in new product development through knowledge management: a practitioner perspective." Journal of Engineering and Technology Management, 20(1), pp. 117140.

5) Gidel, T., Gautier, R. \& Duchamp, R. (2005). "Decision-making framework methodology: An original approach to project risk management in new product design". Journal of Engineering Design, 16(1), pp. 1-23.

6) Kayis, B., Arndt, G., \& Zhou, M. (2007). "A risk mitigation methodology for new product and process design in concurrent engineering projects". CIRP ANNALS Manufacturing Technology, 56(1), pp. 167-170.

7) Keizer, J.A., Vos, J. \& Halman, J.I.M. (2005). "Risks in new product development: Devising a reference tool”. R\&D Management, 35(3), pp. 297-309.

8) Ninković, D., Sedmak, A., Rakonjac, I., Misita, M. (2012) „Information-communication and Documentation Flow within R\&D Function Model“. Technics Technology Education Management, 7(1), pp. 137-146.

9) Oehmen, J., Olechowski, A., Kenley, C.R. \& Ben-Daya, M. (2014). "Analysis of the effect of risk management practices on the performance of new product development programs". Technovation, 34(8), pp. 441-453.

10) Rakonjac, I., Rakonjac, I., Kirin, S., Spasojević-Brkić, V., Sedmak, A. (2011). "Risk Analysis by Key-coefficient Assessment - Public Lighting Project Example". Technics Technology Education Management, 6(4), pp. 1016-1023. ISSN 1840-1503.

11) Rakonjac, I., Rakonjac, I., Fotirić, N., Rajković, I., Gašić, M (2016). "Analiza svetlosnih karakteristika u eksploatacionom veku instalacije osvetljenja / Lighting Features Life Cycle Analysis for a Lighting System". Structural Integrity and Life, 16(2), pp. 81-86. EISSN:1820-7863, ISSN:1451-3749.

12) Spasojević-Brkić, V., Veljković, Z. \& Golubović, T. (2015). "Fulfilling the requirements for export of metal industry products from Serbia and Bosnia and Herzegovina cross-border area to EU market". Journal of Applied Engineering Science - JAES, 13(3), pp. 25-36. DOI: 10.5937/jaes13-7785. ISSN: 1451-4117.

13) Stanisavljev, S., Ćoćkalo, D., Klarin, M., Spasojević, B.V. \& Đorđević, D. (2015). „Stohastic Model to Determine the Elements of the Production Cycle Time: Case of Serbian Textile Industry". Fibres \& Textiles in Eastern Europe, 23(5), pp. 23-29.

14) Stamenković, D., Popović. V., Spasojević Brkić, V. \& Radivojević, J. (2011). "Combination free replacement and pro-rata warranty policy optimization model". Journal of Applied Engineering Science, 9(4), 456-464. DOI: 10.5937/JAES9 - 1202. ISSN: pp. 14514117.

Paper sent to revision: 02.08.2016.

Paper ready for publication: 07.05.2017. 